\title{
Efficacy and safety of artemether- lumefantrine for treatment of uncomplicated Plasmodium falciparum malaria in Ethiopia: a systematic review and meta-analysis
}

\author{
Abdulhakim Abamecha 1,3,4,6*0 , Daniel Yilma ${ }^{2,3}$, Wondimagegn Adissu ${ }^{1,3}$, Delenasaw Yewhalaw ${ }^{1,4}$ and \\ Alemseged Abdissa $1,3,5$
}

\begin{abstract}
Background: Regular monitoring of anti-malarial drug efficacy is vital for establishing rational malaria treatment guidelines and ensuring adequate treatment outcomes. This study aimed to synthesize the available evidence on the efficacy of artemether-lumefantrine for the management of uncomplicated falciparum malaria in Ethiopia.

Methods: The Preferred Reporting Items for Systematic Reviews and Meta-Analyses (PRISMA) guidelines were followed. Relevant published studies were searched from the databases (PubMed, Google Scholar and Clinical trial registry) on published artemether-lumefantrine therapeutic efficacy studies conducted in Ethiopia from 2004 to 2020. The retrieved studies were assessed for quality using the modified Newcastle Ottawa Scale for observational studies and modified Jadad scale for interventional studies. Risk of bias was also assessed by using ROBINS-I tool. OpenMeta-Analyst software was used for the statistical analysis. The review protocol is registered in PROSPERO, number CRD42020201859.

Results: Fifteen studies (1523 participants) were included in the final analysis. The overall PCR-uncorrected pooled proportion of treatment success of artemether-lumefantrine therapy for uncomplicated falciparum malaria was 98.4\% (95\%Cl 97.6-99.1). A random-effects model was used because of considerable heterogeneity $\left[x^{2}=20.48, d f\right.$ (14), $P=0.011$ and $\left.I^{2}=31.65\right]$. PCR-corrected pooled proportion of treatment success of artemether-lumefantrine therapy was $98.7 \%$ (95\% Cl 97.7-99.6). A random-effects model was used $\left[X^{2}=7.37, d f(6), P=0.287\right.$ and $\left.I^{2}=18.69\right]$. Most studies included in the present review achieved a rapid reduction of fevers and parasitaemia between D0 and D3 of assessment. Adverse events were mostly mild and only two cases were reported as serious, but were not directly attributed to the drug.
\end{abstract}

Conclusion: The present meta-analysis suggests that artemether-lumefantrine therapy is efficacious and safe in treating uncomplicated falciparum malaria in Ethiopia. However, owing to the high risk of bias in the included studies, strong conclusions cannot be drawn. Further high-quality RCTs assessing anti-malarial efficacy and safety should be performed to demonstrates strong evidence of changes in parasite sensitivity to artemether-lumefantrine in Ethiopia. Keywords: Therapeutic efficacy, Artemether-lumefantrine, Plasmodium falciparum, Systematic review, Ethiopia

*Correspondence: abdulhakimbamecha@gmail.com

${ }^{1}$ School of Medical Laboratory Sciences, Institute of Health, Jimma University, Jimma, Ethiopia

Full list of author information is available at the end of the article

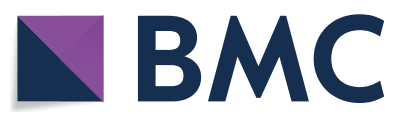

(c) The Author(s) 2021. This article is licensed under a Creative Commons Attribution 4.0 International License, which permits use, sharing, adaptation, distribution and reproduction in any medium or format, as long as you give appropriate credit to the original author(s) and the source, provide a link to the Creative Commons licence, and indicate if changes were made. The images or other third party material in this article are included in the article's Creative Commons licence, unless indicated otherwise in a credit line to the material. If material is not included in the article's Creative Commons licence and your intended use is not permitted by statutory regulation or exceeds the permitted use, you will need to obtain permission directly from the copyright holder. To view a copy of this licence, visit http://creativeco mmons.org/licenses/by/4.0/. The Creative Commons Public Domain Dedication waiver (http://creativecommons.org/publicdomain/ zero/1.0/) applies to the data made available in this article, unless otherwise stated in a credit line to the data. 


\section{Background}

Malaria is one of the leading health problems in Ethiopia. Approximately $60 \%$ of the total populations in Ethiopia live in malaria-endemic area. Due to the unstable nature of malaria transmission in the country, major malaria epidemics had been one of the serious public health emergencies. Sixty percent of malaria infections in Ethiopia are due to Plasmodium falciparum and $40 \%$ of infections are due to Plasmodium vivax [1, 2].

Resistance of $P$. falciparum to the traditional antimalarial drugs (such as chloroquine, sulfadoxinepyrimethamine, amodiaquine, and mefloquine) is a growing problem and is thought to have contributed to increased malaria mortality in recent years [3]. Chloroquine resistance has now been documented in all regions except Central America and the Caribbean. There is highlevel resistance to sulfadoxine-pyrimethamine throughout South East Asia and increasingly in Africa, including Ethiopia, and mefloquine resistance is common in the border areas of Cambodia, Myanmar, and Thailand [3, 4].

To combat the spread of resistance, the World Health Organization (WHO) now recommends that $P$. falciparum malaria should always be treated using a combination of two drugs that act at different biochemical sites within the parasite [3]. If a parasite mutation producing drug resistance arises spontaneously during treatment, the parasite should then be killed by the partner drug, thus reducing or delaying the development of resistance and increasing the useful lifetime of the individual drugs $[5,6]$. The current drug combinations all include a short-acting artemisinin derivative (such as artesunate, artemether, or dihydroartemisinin), partnered with a longer-acting drug in combinations known as 'artemisinin-based combination therapy' (ACT). In Ethiopia, the use of artemether-lumefantrine $(20 / 120 \mathrm{mg})$ as the first-line treatment for uncomplicated falciparum malaria has been started in 2004 [7].

The potency of artemisinin and its derivatives such as artemether, dihydroartemisinin, and artesunate is very high against all erythrocytic cycle asexual stages of $P$. falciparum with preference to the young ring stages [8], so much that it reduces the parasite biomass by 100 to 10,000 folds per each asexual blood stage cycle (after $48 \mathrm{~h}$ ). It also kills young gametocytes, hence playing a role in reducing malaria transmission [9]. The proposed mechanisms by which artemisinins kill the parasites are quite broad and are still being studied, but they generally fall under two categories: (1) Damaging parasite proteins, such as transport proteins through haem-activated endoperoxide activity and (2) Inhibition of proteasome activity (parasite's cellular repair mechanisms) leading to accumulation of damaged/unfolded proteins and stressinduced death [10-14].
Due to the risk of the emergence and spread of antimalarial drug resistance, the WHO recommends regular monitoring of anti-malarial drug efficacy at least every 2 years in malaria-endemic countries [15]. In Ethiopia, the Federal ministry of Health (FMOH), in collaboration with its partners, including President's Malaria Initiative (PMI), research institutions, universities, WHO country office and Global fund, have been conducting regular therapeutic efficacy studies (TESs). The efforts of the FMOH to ensure regular TESs have also been complemented by TESs conducted by independent researchers $[16,17]$.

A meta-analysis of AL efficacy studies in Ethiopia was also carried out in 2017, but had several limitations including failure to assess risk of bias and missed studies $[18,19]$. Hence, this study aimed to synthesize the available evidence, including new studies and studies that were missed in the previous meta-analysis, on the efficacy of AL for the management of uncomplicated falciparum malaria in Ethiopia.

\section{Methods \\ Study protocol registration}

The present study adhered to the preferred reporting items for systematic reviews and meta-analyses (PRISMA)guideline [20]. The completed PRISMA checklist is available in Additional file 1. The review protocol was registered in a repository of systematic review protocols prior to starting the research (PROSPERO, protocol number CRD42020201859) [21].

\section{Searching strategies}

The searching strategy was performed using approaches that enhance methodological transparency and improve the reproducibility of the results and evidence synthesis. In this sense, the search strategy was elaborated and implemented prior to study selection, according to the PRISMA checklist as guidance [20]. Additionally, using the Population, Intervention, Comparison, Outcome and Study design (PICOS) strategy [22, 23]. The following major databases were searched: PubMed, Google Scholar, and ClinicalTrials.gov databases. In order to reflect contemporary practice, a search of the literature from the last 16 years (January 2004 to October 2020) was performed. The starting year (i.e., 2004) was purposely chosen because that was the year when Ethiopia adopted use of AL for treating uncomplicated falciparum malaria [24]. The date of the last search was 30th October 2020.

The search terms were developed in line with the Medical Subject Headings (MeSH) thesaurus using a combination of the big ideas (or "key terms") which derived from the research question. The domains of the search terms were: "efficacy", "therapeutic efficacy", 
"artemether-lumefantrine", "Coartem", "Plasmodium falciparum malaria", "falciparum malaria”, "antimalarial drug", and "Ethiopia". This study combined terms using the Boolean operator "OR" and "AND" accordingly [25]. Search was limited to studies published in English language until October 2020. Full search strategy for the databases is provided in Additional file 2. Two reviewers (AbAb, and WA) reviewed the search results independently to identify relevant studies. Also, the bibliographic software EndNote X5 citation manager (Thomson Reuters, New York, USA) was used to store, organize and manage all the references and ensure a systematic and comprehensive search.

\section{Selection criteria}

Eligible studies included randomized controlled trials (RCTs), non-randomized single-arm intervention studies (with or without a control group) and prospective cohort studies. This study intended to only include studies with a comparator or control group, but because of the varying quality of papers retrieved, the study methodology deviated from the original methodologic plan and included any study describing patients given a treatment of interest (i.e. AL), which advise a 28-day follow-up to capture cure rate, even if no specific control group was available. All the non-primary literature, retrospective studies, case reports and in vitro experiments were excluded.

A summary of the participants, interventions, comparators and outcomes considered, as well as the type of studies included according to PICOS criteria[22, 23], which is provided in Table 1 . The primary objective of this review was the efficacy of AL measured as treatment success at day 28 (or adequate clinical and parasitological response (ACPR). ACPR is defined by the WHO as the "absence of parasitaemia on day 28 irrespective of axillary temperature, in patients who did not previously meet any of the criteria of early treatment failure, late clinical failure or late parasitological failure" [15]. This is also consistent with previous Cochrane Reviews. The secondary endpoints were fever clearance, parasite clearance, and the frequency of adverse drug reactions (ADRs). ADRs were defined as 'signs and symptoms that first occurred or became more severe after treatment was started' or 'as a sign, symptom, or abnormal laboratory value not present on day 0 , but which occurred during follow up, or was present on day 0 but became worse during follow up' Serious adverse events were defined according to International Conference on Harmonization ( $\mathrm{ICH}$ ) guidelines. Studies included in this review are shown in Table 2.

\section{Data extraction and management}

Initial screening of studies was based on the information contained in their titles and abstracts and was conducted by two independent investigators. When the reviewers disagreed, the article was re-evaluated and, if the disagreement persisted, a third reviewer made a final decision. Full-paper screening was conducted by the same independent investigators.

Data were extracted using a case record form (CRF), including four domains: (1) identification of the study (article title; journal title; authors name; country of the study; language, publication year and study setting); (2)

Table 1 PICOS strategy and eligibility criteria

\begin{tabular}{|c|c|c|}
\hline PICOS Strategy & Inclusion criteria & Exclusion criteria \\
\hline P:Population & $\begin{array}{l}\text { Participants residing in Ethiopia and having uncomplicated } \\
\text { falciparum malaria, irrespective of gender and age group } \\
\text { were considered. Microscopy of the peripheral blood smear } \\
\text { samples detected mono-infection with a P. falciparum parasite } \\
\text { count of } 1000-100,000 / \mu l\end{array}$ & \\
\hline I: Intervention & $\begin{array}{l}\text { Studies using fixed dose compound tablets artemether-lume- } \\
\text { fantrine }(20 / 120 \mathrm{mg}) \text { were included. All participants must have } \\
\text { received a standard six-dose regimen of AL over } 3 \text { days and } \\
\text { were followed up for } 28 \text { days }\end{array}$ & \\
\hline C:Comparison & Standard treatment, no treatment, not applicable & \\
\hline O: Outcome & $\begin{array}{l}\text { The primary objective of this review was the efficacy of AL } \\
\text { measured as treatment success at day } 28 \text { [or adequate clinical } \\
\text { and parasitological response (ACPR)]. The secondary outcomes } \\
\text { were measured based on the parasite clearance time and fever } \\
\text { clearance time and the occurrence of adverse events (AEs) }\end{array}$ & $\begin{array}{l}\text { Studies that do not report any treatment success (cure rates) of AL } \\
\text { at day-28 as primary outcome }\end{array}$ \\
\hline S: Study design & $\begin{array}{l}\text { Randomized clinical trials (RCTs), non-randomized single-arm } \\
\text { intervention studies (with or without a control group) and } \\
\text { prospective cohort studies that reported the therapeutic } \\
\text { efficacy of AL for the treatment of uncomplicated falciparum } \\
\text { malaria in Ethiopia }\end{array}$ & $\begin{array}{l}\text { All the non-primary literature, retrospective studies, case reports } \\
\text { and animal or in vitro experiments were excluded }\end{array}$ \\
\hline
\end{tabular}




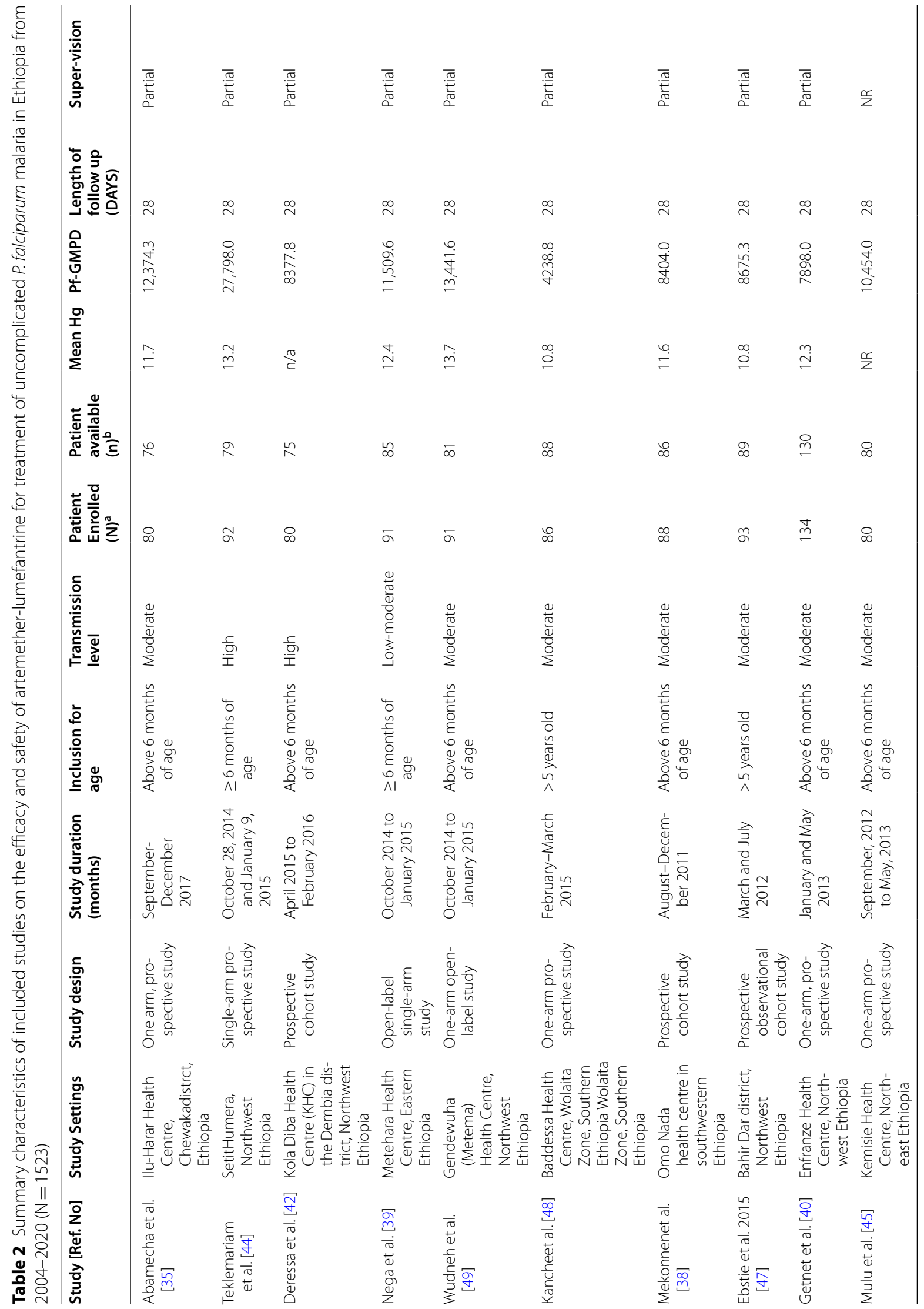




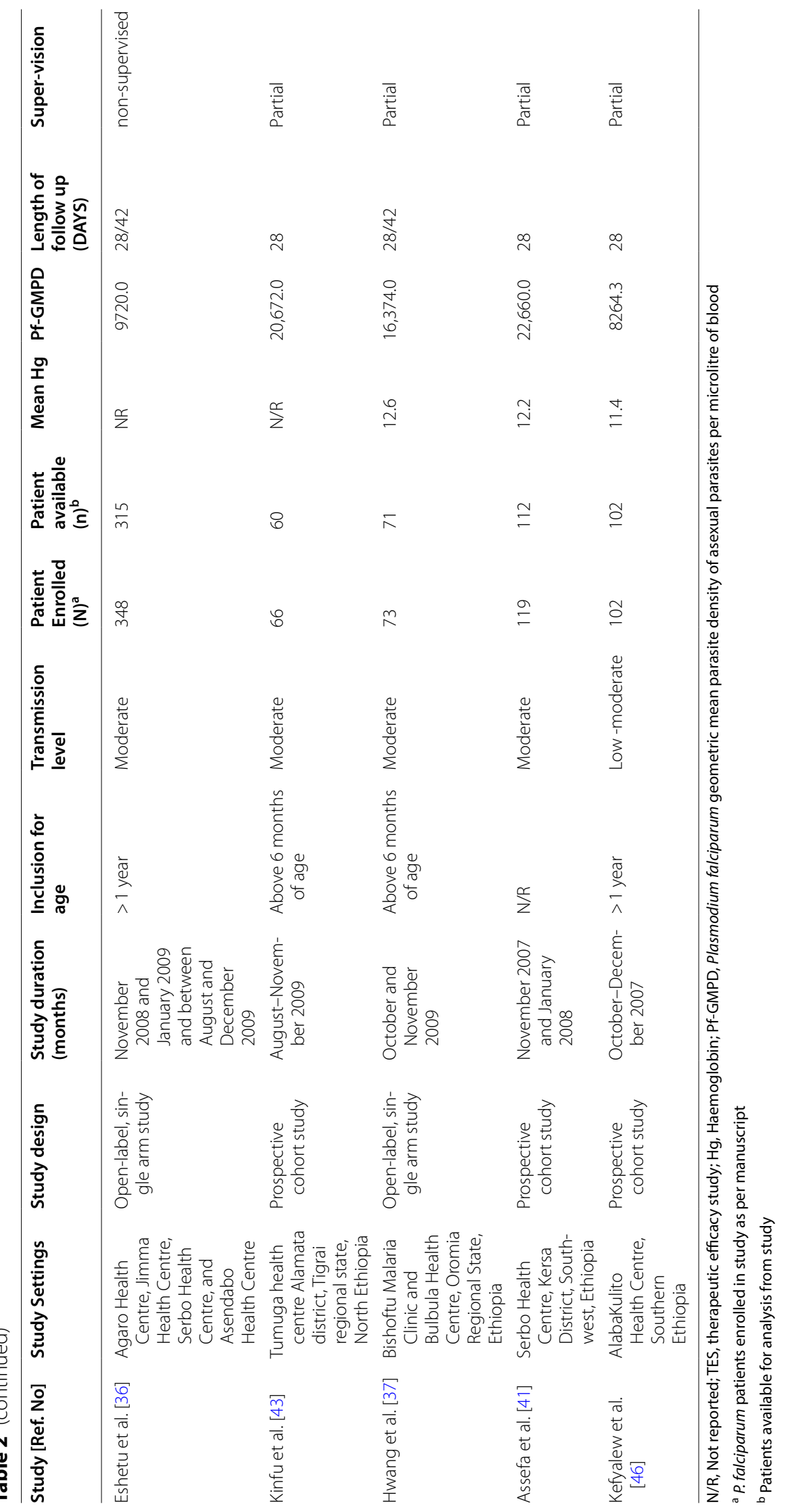


methodological characteristics (study design; stated length of follow-up; sample size; gender; age; intervention details; literature quality assessment characteristics; statistical analyses); (3) main findings (treatment success rates; parasite clearance; fever clearance; adverse events) and (4) conclusions. If the outcome data in the original article were unclear, the corresponding author was contacted via email for clarification. A bibliographic software EndNote X5 citation manager (Thomson Reuters, New York, USA) was used to store, organize and manage all the references and ensure a systematic and comprehensive search.

\section{Methodological quality assessment}

Two review authors independently assessed the methodological quality of the selected studies by using methodological quality assessment forms and the criteria outlined in the Cochrane Handbook for Systematic Reviews of Interventions [22, 23].Any disagreements between the two review authors were resolved through discussion. Quality assessment was undertaken using the Newcastle Ottawa Scale (NOS) for observational studies [26] and modified Jadad scale for interventional studies [27]. NOS assess the quality under three major headings, namely, selection of the studies (representativeness and the exposure assessment/control selection), comparability (adjustment for main/additional confounders), and outcome/exposure (adequacy of outcome measured, exposure measured vs. self-report) (Additional file 3). The modified Jadad scale included eight items: randomization, blinding, withdrawals, dropouts, inclusion/ exclusion criteria, adverse effects and statistical analysis. The reviewers independently assessed the quality of the methodology of included studies (Additional file 4). This study also assessed using Risk of Bias in Non-Randomized Studies of Interventions (ROBINS-I) assessment tool for non-randomized intervention and cohort studies. Studies were ranked as low, moderate, serious, or critical risk of bias in seven domains [28].

\section{Statistical analysis}

OpenMeta Analyst software for Windows [29, 30] was used to perform the meta-analyses. The heterogeneity of the included studies was evaluated using the Cochran Q and $\mathrm{I}^{2}$ statistics. The random effects model was used as standard in the determination of heterogeneity between studies [31]. The $\mathrm{I}^{2}$ values were expressed in percentages. Heterogeneity was classified as low, moderate and high, with upper limits of $0-25 \%, 25-50 \%$ and $>50 \%$ for $\mathrm{I}^{2}$, respectively $[32,33]$. The method of random effects model was used to combine the included studies.

\section{Results}

\section{Literature search results}

A total of 1043 studies were retrieved from the database and manual searching. Among these, 724 duplicated studies were excluded. From the remaining 319 articles, 303 of them were excluded after evaluation of their title and abstract confirming non relevance to this study. One paper [34] was excluded following full text review as data collection for the study was conducted before official adoption of AL in Ethiopia. Finally, a total of 15 papers met the eligibility criteria and were included in this systematic review and meta-analysis (Fig. 1).

\section{Characteristics of the included studies}

The summary characteristics of the included studies are shown in Table 2. From 15 eligible studies a total 1523 participants were included. Seven of the studies were interventional [35-41], and the other eight studies were observational study [42-49]. No RCTs had been completed at the time of review. These studies were conducted in different malarious parts of the country with varied transmission intensity (Fig. 2). Most (10/15, 66.7\%) of the studies included patients who were $\geq 6$ months of age (Table 2). Treatment outcomes in all studies were assessed using clinical and parasitological criteria according to WHO guidelines [15]. In the majority of the studies (86.7\%), treatment compliance was assured by supervised administration of the study drug under direct observation on days 1,2 and 3 , i.e. the morning doses were directly observed over 3 days, while the evening doses were given to patients for intake at home by health extension workers. The endpoint was day 28 in all studies [15]. RoB assessment is shown for all studies in Table 5.

\section{Treatment outcome}

The overall PCR-uncorrected pooled proportion estimate of treatment success of AL therapy for uncomplicated falciparum malaria was $98.4 \%$ (95\%CI 97.6-99.1). A random-effects model was used because of substantial heterogeneity $\left[\mathrm{X}^{2}=20.48, d f(14), P=0.011\right.$ and $\mathrm{I}^{2}=31.65$; Fig. 3]. PCR-corrected pooled proportion of treatment success of AL therapy was $98.7 \%$ (95\% CI 97.7-99.6). A random-effects model was used $\left[x^{2}=7.37, d f(6)\right.$, $P=0.287$ and $\mathrm{I}^{2}=18.69$; Fig. 4$]$.

The proportion of recurrence infection was ranging from $1-5.6 \%$ at 28 -day follow-up period after treatment with AL. The proportion of recurrence infection was ranging from $4.6-6.7 \%$ at 42 -day follow-up period after treatment with AL.

The PCR-corrected cure rates of AL therapy ranged from 95.0 to $99.4 \%$ in per-protocol analysis and 88.8 to $97.4 \%$ in intention-to-treat analysis. The percentage of ACPR and the $95 \% \mathrm{CI}$ are presented in Table 3. The 


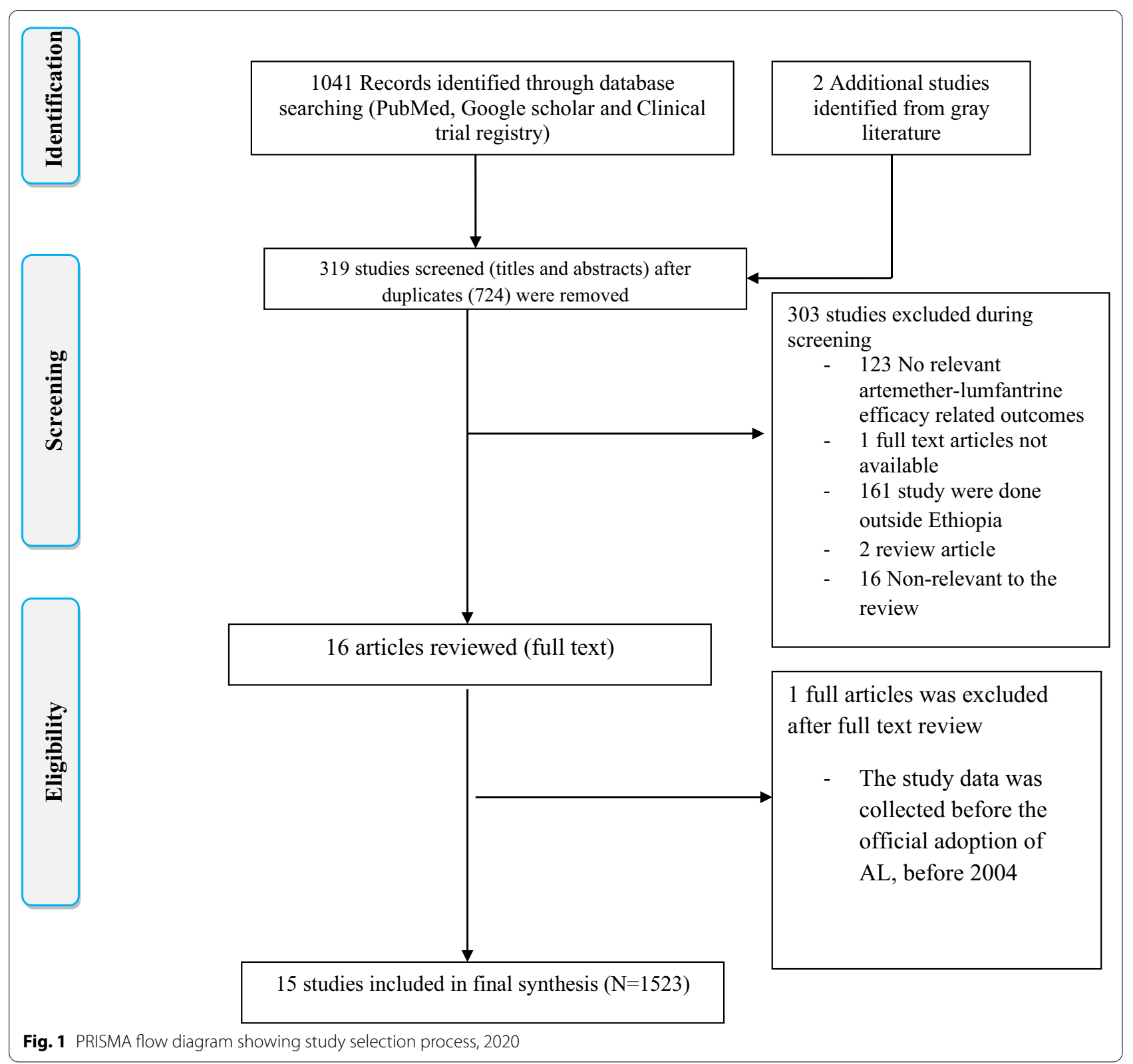

highest cure rate 99.4\% (95\% CI 97.4-100.0) was reported by study conducted in Jimma Zone, Southwest Ethiopia in 2012 [36], and 97.4\% (95\% CI 93.9-100) reported by study conducted in Bishoftu Malaria Clinic and Bulbula Health Centre, Oromia Regional State, Ethiopia 2011 [37].

\section{Fever and parasite clearance rate}

Among the five partially supervised efficacy studies that reported fever clearance, more than $75 \%$ of the patients cleared fever by day 1 post-treatment with $\mathrm{AL}$ [38-43]. Some authors did not measure fever clearance on subsequent days post drug administration and only choose day-3 for this clinical measurement [41, 47]. Among the fifteen studies that reported parasite clearance, five studies showed day-3 parasitaemic cases of $5.7 \%, 5.1 \%, 5 \%, 3.9 \%$ and $3.8 \%$ [35, 40, 42, 47, 48]. Table 4 shows the overall progress of fever and parasite clearance in the first three days of AL treatment.

\section{Safety outcomes}

The current meta-analysis showed that $80 \%$ of the included studies reported ADRs to AL which were observed in $36.1 \%$, (550/1523) patients. All of the ADRs 
Distribution of artemether-lumefantrine therapeutic efficacy and safety study sites, Ethiopia(2004 - 2020)

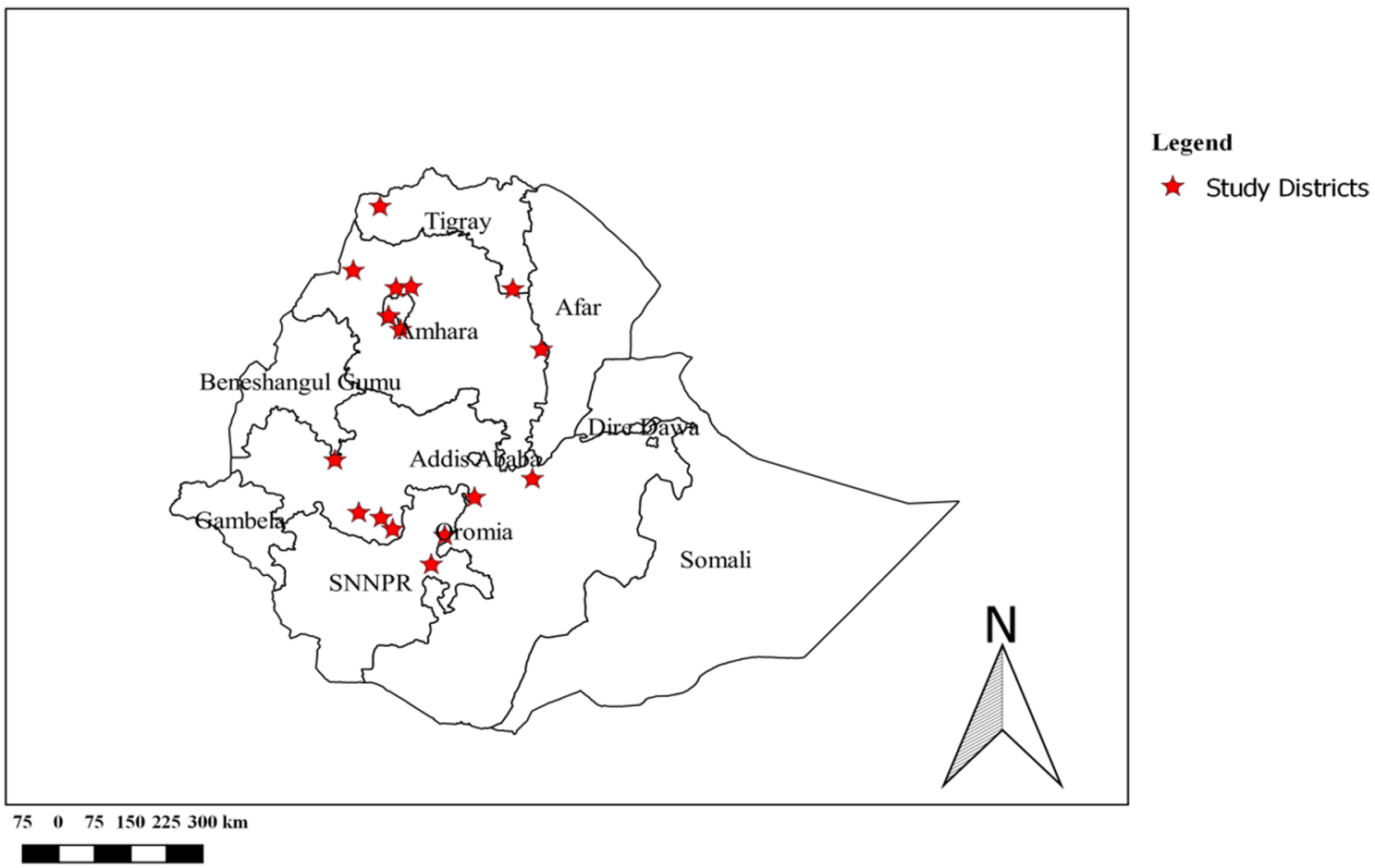

Fig. 2 Distribution of artemether-lumefantrine efficacy and safety study sites in Ethiopia from 2004-2020

were mild and resolved spontaneously. Two SAE were observed (Additional file 5).

\section{Methodological quality assessment}

Eight observational studies [42-49] were assessed with the Newcastle Ottawa Scale (NOS) [26] with satisfactory qualities with a value score of 5 (Additional file 3) and while the remaining seven interventional studies [35-41] were assessed using the modified Jadad scale [27] with high qualities with a value score of 4 (Additional file 4). All or most of the included studies had a 'serious' or 'critical' risk of bias due to confounding because most were single-arm studies (Table 5).

\section{Discussion}

The present study found high treatment success of $\mathrm{AL}$ therapy in the treatment of uncomplicated falciparum malaria in Ethiopia despite its use for more than 16 years. Besides, AL was generally a safe treatment. Previous meta-analysis in 2017 revealed similarly high efficacies of AL $[18,19]$. This result is also consistent with neighbouring Sudan, a high treatment success rate (98\%) of malaria treatment was recently reported in a meta-analysis that included 20 studies with a total of 4070 patients [50]. The treatment success of $98.7 \%$ (95\% CI 97.7-99.6) found in this study suggests that, in accordance with WHO parameters [15], AL is still effective as first-line drug for uncomplicated malaria treatment in Ethiopia, but warrants regular monitoring.

There is a concern about the limited post-treatment prophylactic effects of AL in high transmission areas [15]. In this study, the proportion of recurrence infection ranging from 1 to $5.6 \%$ at 28 -day follow-up period after treatment with AL. From the included studies, two studies [36, 37] also had 42-day follow up period, and the proportion of recurrence infection were relatively high (ranging from 4.6-6.7\%). The study results showed that most recurrent parasitaemia occur after day 28 and this emphasizes the need for follow-up periods of at least 42 days. High recurrent parasitaemia rate in children $\leq 5$ years $(9.4 \%)$ was observed, which suggest that the partner drug may not provide prolonged protection despite high therapeutic efficacy [51].This observation has also been reported in Democratic Republic of Congo, which showed high level of resistance to lumefantrine [52]. In most of the studies, a great majority of the recurrent infections were due to re-infections when assessed with a step-wise PCR genotyping protocol. This signifies that the drugs are still efficacious and the high rates of re-infections could only be attributed to high malaria transmission. In terms of 


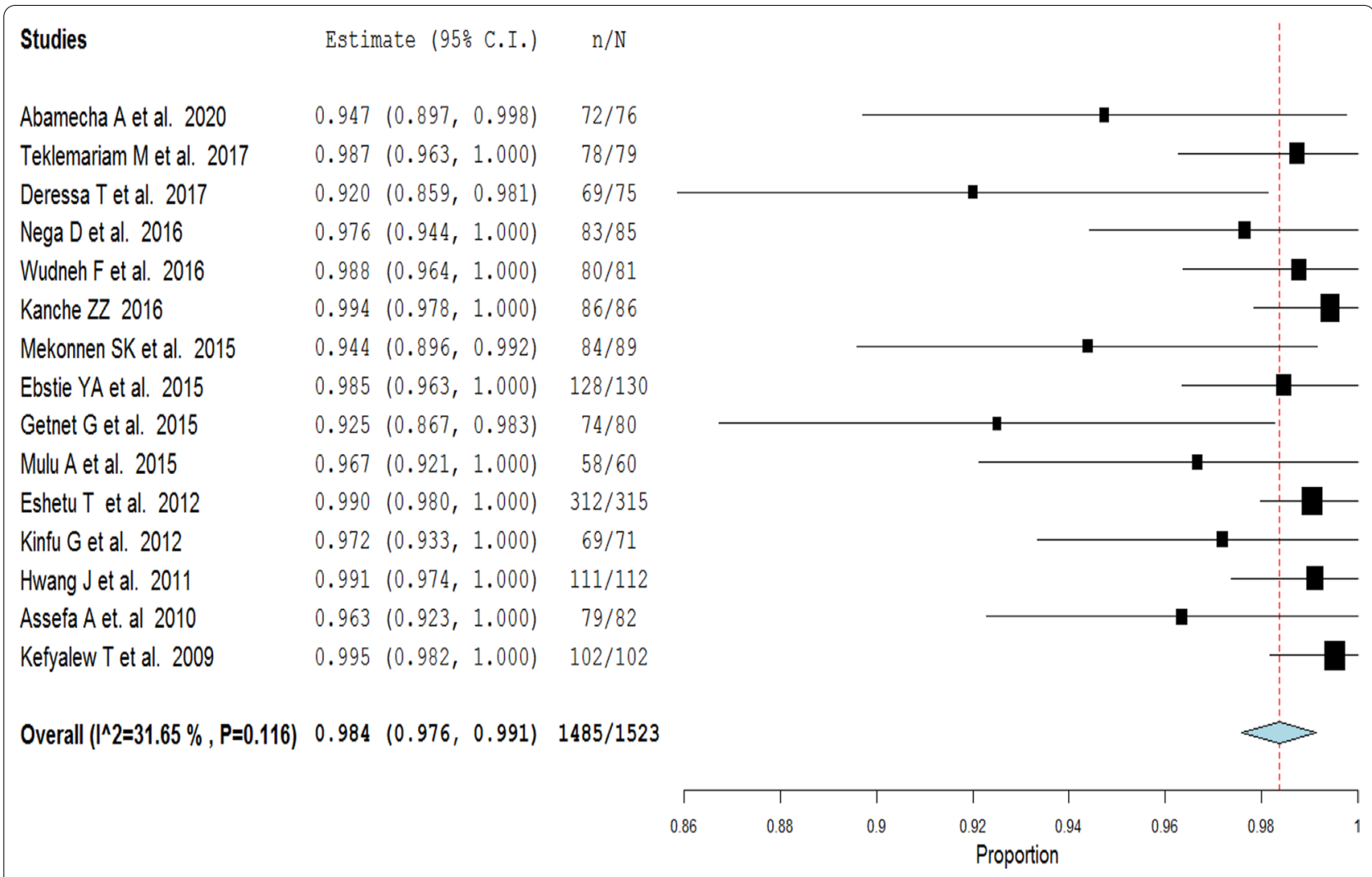

Fig. 3 PCR-uncorrected treatment success of artemether-lumefantrine therapy using a random effect model

\begin{tabular}{|c|c|c|c|c|c|c|}
\hline Studies & Estimate (95\% C.I.) & $\mathrm{n} / \mathrm{N}$ & & & & \\
\hline Abamecha A et al. 2020 & $0.960(0.916,1.000)$ & $72 / 75$ & & & - & \\
\hline Nega D et al. 2016 & $0.988(0.965,1.000)$ & $83 / 84$ & & & & \\
\hline Mekonnen SK et al. 2015 & $0.978(0.947,1.000)$ & $87 / 89$ & & & & \\
\hline Getnet $G$ et al. 2015 & $0.950(0.902,0.998)$ & $76 / 80$ & & & & \\
\hline Eshetu T et al. 2012 & $0.994(0.985,1.000)$ & $312 / 314$ & & & & \\
\hline Hwang J et al. 2011 & $0.991(0.974,1.000)$ & $111 / 112$ & & & & \\
\hline Assefa A et. al 2010 & $0.963(0.923,1.000)$ & $79 / 82$ & & & & \\
\hline \multirow[t]{3}{*}{ Overall $\left(I^{\wedge} 2=18.69 \%, P=0.287\right)$} & $0.987(0.977,0.996)$ & $820 / 836$ & & & & \\
\hline & & & $\Gamma$ & 1 & $T$ & $T$ \\
\hline & & & 0.92 & 0.94 & 0.96 & 0.98 \\
\hline
\end{tabular}

clinical practice, the high re-infection rates are of great concern among clinicians. Clinicians should be clearly guided on what to expect and how to handle such cases with recurrent infections within a period of three to eight weeks post-treatment. The observed high re-infection rates after $\mathrm{AL}$ treatment underscores the importance of 
Table 3 Treatment Outcome of AL Therapy reported in efficacy studies in Ethiopia

\begin{tabular}{lcc}
\hline Study & PP PCR-corrected percentage cure rate (95\% Cl), day-28 & $\begin{array}{l}\text { ITT PCR-corrected } \\
\text { percentage cure rate (95\% } \\
\text { Cl), day-28 }\end{array}$ \\
\hline Abamecha et al. [35] & & $94.9(90.1-99.8)$ \\
Nega et al. [39] & $96.0(91.6-100)$ & $92.2(86.7-97.8)$ \\
Mekonnen et al. [38] & $98.8(96.5-100)$ & $96.7(93.0-100)$ \\
Getnet et al. [40] & $97.8(94.7-99.8)$ & $97.4(93.9-100)$ \\
Eshetu et al. [36] & $95.0(90.2-100)$ & $89.9(86.7-93.1)$ \\
Hwang et al. [37] & $99.4(97.4-100)$ & $94.1(89.9-98.3)$ \\
Assefa et al. [41] & $99.1(91.6-100)$ & $88.8(82.2-95.3)$
\end{tabular}

Table 4 Fever and parasite clearance reported in efficacy studies in Ethiopia (2004-2020)

\begin{tabular}{|c|c|c|c|c|c|c|c|c|c|c|}
\hline \multirow[t]{2}{*}{ Study } & \multirow{2}{*}{$\begin{array}{l}\text { Patient } \\
\text { Enrolled (N) }\end{array}$} & \multirow{2}{*}{$\begin{array}{l}\text { Patient } \\
\text { available }\end{array}$} & \multirow{2}{*}{$\begin{array}{l}\text { Patient } \\
\text { Included }\end{array}$} & \multicolumn{3}{|c|}{ Fever clearance (\%) } & \multicolumn{3}{|c|}{ Parasite clearance (\%) } & \multirow[t]{2}{*}{ Supervised } \\
\hline & & & & D1 & D2 & D3 & D1 & D2 & D3 & \\
\hline Abamecha et al. [35] & 80 & 76 & 72 & 52.5 & 87.2 & 97.5 & 61.2 & 81.2 & 96.2 & Partial \\
\hline Teklemariam et al. [44] & 92 & 79 & 78 & 80.0 & 97.8 & 100.0 & 33.0 & 84.4 & 100.0 & Partial \\
\hline Deressa et al. [42] & 80 & 75 & 69 & 62.5 & 93.7 & 97.5 & 67.5 & 85.0 & 95.0 & Partial \\
\hline Nega et al. [39] & 91 & 85 & 83 & 78.7 & 94.3 & 97.7 & 69.7 & 95.5 & 100.0 & Partial \\
\hline Wudneh et al. [49] & 91 & 81 & 80 & 69.6 & 97.8 & 100.0 & 23.6 & 91.0 & 100.0 & Partial \\
\hline Kanche et al. [48] & 88 & 86 & 86 & $N / R$ & 59.1 & 93.2 & $N / R$ & 72.2 & 94.3 & Partial \\
\hline Mekonnen et al. [38] & 93 & 89 & 84 & 88.1 & 94.4 & 100.0 & 88.8 & 96.6 & 100.0 & Partial \\
\hline Ebstie et al. [47] & 134 & 130 & 128 & NR & $N R$ & 87.9 & $N R$ & 85.9 & 96.1 & Partial \\
\hline Getnet et al. [40] & 80 & 80 & 74 & 75.0 & 91.3 & 96.2 & 73.8 & 91.3 & 94.9 & Partial \\
\hline Mulu et al. [45] & 66 & 60 & 58 & 89.4 & 98.5 & 100.0 & 84.8 & 93.9 & 100.0 & $\mathrm{NR}$ \\
\hline Eshetu et al. [36] & 348 & 315 & 312 & NR & 96.7 & 99.1 & $N R$ & 98.2 & 99.4 & Non-supervised \\
\hline Kinfu et al. [43] & 73 & 71 & 69 & NR & $N R$ & 100.0 & NR & 100.0 & 100.0 & Partial \\
\hline Hwang et al. [37] & 119 & 112 & 111 & 65.2 & 90.5 & 93.0 & NR & 93.1 & 99.1 & Partial \\
\hline Assefa et al. [41] & 90 & 82 & 79 & $N R$ & $N R$ & 100 & 98 & NR & 100.0 & Partial \\
\hline Kefyalew et al. [46] & 102 & 102 & 102 & 44.1 & 82.4 & 93.1 & NR & NR & NR & Partial \\
\hline
\end{tabular}

providing anti-malarial drug with a longer period of protection against re-infection, such as DHA-piperaquine [53] and integrating treatment with non-therapeutic prevention and control measures (insecticide-treated bed nets, indoor residual spraying and other vector control measures) to effectively prevent recurrent infections [54, 55]. Besides, it is also important to use transmissionblocking drugs (e.g. use of primaquine) (gametocytocidal) in low transmission areas.

Most studies included in the present review achieved a rapid reduction of fevers and parasitaemia between D0 and D3 of assessment. A previous aggregate study on the clinical predictors of early parasitological response to ACT in African patients with uncomplicated falciparum malaria confirmed the rapid decrease of parasite positivity rate from $59.7 \%$ (95\% CI $54.5-64.9)$ on day 1 to $6.7 \%$ (95\% CI 4.8-8.7) on day 2 and $0.9 \%$ (95\% CI $0.5-1.2)$ on day 3 [56].
In resource-limited settings, the day-3 parasite-positive rate can be used as a proxy measure of delayed parasite clearance [57]. In the present review, few studies showed day-3 parasitaemic cases (3.8-5.7\%) after treatment with $\mathrm{AL}[35,40,42,47,48]$. However, most of the studies reviewed in this article were based on 24-h sampling, which is not the recommended method for assessing parasite clearance and detection of tolerance/resistance to artemisinins.

Regarding safety of AL for treatment of uncomplicated malaria, mild adverse events (a headache, cough, fever, diarrhoea, vomiting, perioral ulcer, anorexia, abdominal pain, dizziness and nausea, weakness/fatigue and others) were mostly reported in the eligible studies. Besides, almost all were resolved soon after completion of the treatment except cough [35, 41, 44]. Similar mild adverse events have been associated with AL; the most common being headache, fever, vomiting followed by 
Table 5 Quality assessment by 'Risk of bias in non-randomized studies of interventions (ROBIN-I)' for non-randomized and cohort studies

\begin{tabular}{|c|c|c|c|c|c|c|c|c|c|}
\hline \multirow{2}{*}{ Study[Ref.No] } & \multirow{2}{*}{ Study design } & \multicolumn{8}{|c|}{ Reason for risk of bias (RoB) determination } \\
\hline & & Confounding & $\begin{array}{l}\text { Selection of } \\
\text { participants }\end{array}$ & $\begin{array}{c}\text { Classification of } \\
\text { interventions }\end{array}$ & $\begin{array}{l}\text { Deviations from } \\
\text { intended } \\
\text { interventions }\end{array}$ & $\begin{array}{l}\text { Missing } \\
\text { outcome } \\
\text { data }\end{array}$ & $\begin{array}{c}\text { Outcome } \\
\text { measureme } \\
\text { nts }\end{array}$ & $\begin{array}{l}\text { Selection of } \\
\text { results } \\
\text { reported }\end{array}$ & $\begin{array}{c}\text { Overall } \\
\text { RoB }\end{array}$ \\
\hline Abamecha et al.[35] & $\begin{array}{l}\text { One arm, } \\
\text { prospective } \\
\text { study }\end{array}$ & Serious & Low & Moderate & Moderate & Low & Low & Moderate & Serious \\
\hline Teklemariam et al.[44] & $\begin{array}{l}\text { Single-arm } \\
\text { prospective } \\
\text { study }\end{array}$ & Critical & Low & Moderate & Moderate & Critical & Low & Moderate & Critical \\
\hline Deressa et al.[42] & $\begin{array}{l}\text { Prospective } \\
\text { cohort study }\end{array}$ & Critical & Low & Moderate & Moderate & Critical & Low & Moderate & Critical \\
\hline Nega et al.[39] & $\begin{array}{l}\text { Open-label } \\
\text { single-arm study }\end{array}$ & Serious & Low & Moderate & Moderate & Low & Low & Moderate & Serious \\
\hline Wudneh et al.[49] & $\begin{array}{l}\text { one-arm open- } \\
\text { label study }\end{array}$ & Critical & Low & Moderate & Moderate & Critical & Low & Moderate & Critical \\
\hline Kanche et al.[48] & $\begin{array}{l}\text { One-arm } \\
\text { prospective } \\
\text { study }\end{array}$ & Critical & Low & Moderate & Moderate & Critical & Low & Moderate & Critical \\
\hline Mekonnen et al.[38] & $\begin{array}{l}\text { In-vivo } \\
\text { therapeutic } \\
\text { efficacy study }\end{array}$ & Serious & Low & Moderate & Moderate & Critical & Low & Moderate & Critical \\
\hline Ebstie et al.[47] & $\begin{array}{l}\begin{array}{l}\text { Prospective } \\
\text { observational } \\
\text { cohort study }\end{array} \\
\end{array}$ & Critical & Low & Moderate & Moderate & Critical & Low & Moderate & Critical \\
\hline Getnet et al.[40] & $\begin{array}{l}\text { One arm, } \\
\text { prospective } \\
\text { study }\end{array}$ & Serious & Low & Moderate & Moderate & Critical & Low & Moderate & Critical \\
\hline Mulu et al.[45] & $\begin{array}{l}\text { One-arm } \\
\text { prospective }\end{array}$ & Critical & Low & Moderate & Moderate & Critical & Low & Moderate & Critical \\
\hline & study & & & & & & & & \\
\hline Eshetu et al.[36] & $\begin{array}{l}\text { open-label, } \\
\text { single-arm study }\end{array}$ & Serious & Low & Moderate & Moderate & Low & Low & Moderate & Serious \\
\hline Kinfu et al.[43] & $\begin{array}{l}\text { Prospective } \\
\text { cohort study }\end{array}$ & Critical & Low & Moderate & Moderate & Critical & Low & Moderate & Critical \\
\hline Hwang et al.[37] & $\begin{array}{l}\text { single arm, open } \\
\text { label study }\end{array}$ & Serious & Low & Moderate & Moderate & Low & Low & Moderate & Serious \\
\hline Assefa et al.[41] & $\begin{array}{l}\text { Prospective } \\
\text { cohort study }\end{array}$ & Serious & Low & Moderate & Moderate & Critical & Low & Moderate & Critical \\
\hline Kefyalew et al.[46] & $\begin{array}{l}\text { Prospective } \\
\text { cohort study }\end{array}$ & Critical & Low & Moderate & Moderate & Critical & Low & Moderate & Critical \\
\hline
\end{tabular}

gastrointestinal disturbances $[50,58]$. The observed rate of $36.1 \%$, (550/1523) ADRs was comparable with the rate reported in the previous review in Ethiopia where 269 of 633 patients had ADRs, with a pooled event rate of $41.2 \%$ [19].

From the included studies, one study reported serious adverse events (SAE) in two infants [36]. These infants had SAE on the day of presentation (day-0) with high parasitaemia $(>95,000 / \mu \mathrm{L})$, no signs of severe malaria were noticed at admission and did not tolerate oral treatment. After re-dosing and repeated vomiting, the infants were referred to the ward for intravenous treatment; one died the same day. The cause of death was not established and its possible association with AL treatment could not be ascertained.

\section{Limitation of the review}

This review provided an overall country-specific performance of AL after the wide-scale deployment, since 2004 as first-line anti-malarials for treating uncomplicated P. falciparum malaria in Ethiopia. The main limitation of this work was the lack of a control group in the included studies that severely limits the ability to draw a firm conclusion regarding the efficacy of an intervention. Moreover, there are insufficient number of therapeutic efficacy studies (TESs) studies with high-quality and more rigorous design. This may be due to the fact that TESs and long-term follow-up of patients require logistics and incur high cost in low and middle income countries, limiting regular implementation of clinical evaluation within the country. The current study however 
is the first most comprehensive effort at highlighting the levels of implementation of TESs in Ethiopia and provides an overall country-specific performance of AL after their wide-scale deployment since 2004 as first-line anti-malarials for treating uncomplicated $P$. falciparum malaria in the country.

\section{Conclusions}

The present meta-analysis provides some evidence to support that AL therapy is efficacious and safe in treating uncomplicated falciparum malaria in Ethiopia. However, owing to the risk of bias in the included studies, strong conclusions cannot be drawn. Further high-quality randomized controlled trials are warranted to substantiate the efficacy and safety of AL, to detect future changes in parasite sensitivity to AL in Ethiopia.

\begin{abstract}
Abbreviations
ACPR: Adequate clinical and parasitological response; PCR: Polymerase chain reaction; ACT: Artemisinin-based combination therapy; ADRs: Adverse drug reactions; AE: Adverse events; AL: Artemether-lumefantrine; DHP: Dihydroartemisinin-piperaquine; NOS: Newcastle Ottawa Scale; PICOS: Participants/ population, Intervention, comparator(s), outcome(s), study design; PRISMA: Preferred reporting items for systematic reviews and meta-analyses; RCT: Randomized controlled trials; ROBINS-l: Risk of Bias in Non-Randomized Studies of Interventions; SAE: Serious adverse events; WHO: World Health Organization.
\end{abstract}

\section{Supplementary Information}

The online version contains supplementary material available at https://doi. org/10.1186/s12936-021-03745-8.

Additional file 1. PRISMA Check list.

Additional file 2. Detailed search strategy for the different electronic databases.

Additional file 3. Quality assessment of included studies using Newcastle Ottawa Scale (NOS).

Additional file 4. Quality assessment of included studies using Modified Jadad Scale.

Additional file 5. Safety outcomes of included studies.

\section{Acknowledgements}

We thank the German Academic Exchange Service (DAAD) and Jimma University, Ethiopia for supporting this review.

\section{Authors' contributions}

$\mathrm{AbAb}$ and DaYi conceived and designed the review. AbAb and WA conducted the review and synthesized the findings. AbAb conducted the analysis and wrote the first draft of the manuscript. AbAb, DaYi, WA, DeYe and AIAb revised and edited the manuscript. All authors read and approved the final manuscript.

\section{Funding}

This project was supported in part by DAAD In-Country/In-Region scholarship program 2017. The funders had no role in study design.

\section{Data availability}

All generated data about the review are included in this manuscript. The original data can be accessed from the corresponding author at any time.

\section{Declarations}

Ethics approval and consent to participate

The PRISMA guideline [20] (Additional file 1) recommendations were used and strictly followed to carry out this systematic review and meta-analysis. Ethical approval is not recommended and was not needed since it is a systematic review and meta-analysis.

\section{Consent for publication}

All authors have given their consent for publication.

\section{Competing interests}

The authors declare that they have no competing interests.

\section{Author details}

${ }^{1}$ School of Medical Laboratory Sciences, Institute of Health, Jimma University, Jimma, Ethiopia. ${ }^{2}$ Department of Internal Medicine, Institute of Health, Jimma University, Jimma, Ethiopia. ${ }^{3}$ Clinical Trial Unit, Jimma University, Jimma, Ethiopia. ${ }^{4}$ Tropical and Infectious Diseases Research Center (TIDRC), Jimma University, Jimma, Ethiopia. ${ }^{5}$ Armauer Hansen Research Institute, Addis Ababa, Ethiopia. ${ }^{6}$ Department of Biomedical, College of Public Health and Medical Science, Mettu University, Mettu, Ethiopia.

Received: 6 January 2021 Accepted: 21 April 2021

Published online: 06 May 2021

References

1. Federal Democratic Republic of Ethiopia Ministry of Health. National malaria elimination roadmap. Addis Ababa: Federal Democratic Republic of Ethiopia Ministry of Health; 2016.

2. Federal Democratic Republic of Ethiopia Ministry of Health. National malaria elimination strategic plan 2021-2025. Addis Ababa: Federal Democratic Republic of Ethiopia Ministry of Health; 2020.

3. WHO Global Malaria Programme. Guidelines for the treatment of malaria. Geneva: World Health Organization; 2010.

4. The WorldWide Antimalarial Resistance Network (WWARN) DP Study Group. The effect of dosing regimens on the antimalarial efficacy of dihydroartemisinin-piperaquine: a pooled analysis of individual patient data. PLoS Med. 2013;10:e1001564.

5. White NJ, Olliaro PL. Strategies for the prevention of antimalarial drug resistance: rationale for combination chemotherapy for malaria. Parasitol Today. 1996;12:399-401.

6. White NJ, Nosten F, Looareesuwan S, Watkins WM, Marsh K, Snow RW et al. Averting a malaria disaster. Lancet. 1999:353:1965-7.

7. Federal Democratic Republic of Ethiopia Ministry of Health. Malaria diagnosis and treatment guidelines for health workers in Ethiopia. 2nd ed. Addis Ababa: Federal Democratic Republic of Ethiopia Ministry of Health; 2004

8. Klonis N, Xie SC, McCaw JM, Crespo-Ortiz MP, Zaloumis SG, Simpson JA, et al. Altered temporal response of malaria parasites determines differential sensitivity to artemisinin. Proc Natl Acad Sci USA. 2013;1 10:5157-62.

9. Premji ZG, Kokwaro G, Mwai L, Nzila A, Efferth T, White N, et al. Coartem ${ }^{\circledR}$ : the journey to the clinic. Malar J. 2009;8(Suppl 1):S3.

10. Bridgford JL, Xie SC, Cobbold SA, Pasaje CFA, Herrmann S, Yang T, et al. Artemisinin kills malaria parasites by damaging proteins and inhibiting the proteasome. Nat Commun. 2018;9:3801.

11. Golenser J, Waknine JH, Krugliak M, Hunt NH, Grau GE. Current perspectives on the mechanism of action of artemisinins. Int J Parasitol. 2006:36:1427-41.

12. Shandilya A, Chacko S, Jayaram B, Ghosh I. A plausible mechanism for the antimalarial activity of artemisinin: a computational approach. Sci Rep. 2013;3:2513.

13. White NJ. Clinical pharmacokinetics and pharmacodynamics of artemisinin and derivatives. Trans R Soc Trop Med Hyg. 1994;88(Suppl 1):S41-3.

14. Eckstein-Ludwig U, Webb RJ, Van Goethem IDA, East JM, Lee AG, Kimura $\mathrm{M}$, et al. Artemisinins target the SERCA of Plasmodium falciparum. Nature. 2003:424:957-61. 
15. WHO. Methods for surveillance of antimalarial drug efficacy. Geneva: World Health Organization; 2009.

16. Federal Democratic Republic of Ethiopia Ministry of Health. National malaria guideline. 3rd ed. Addis Ababa: Federal Democratic Republic of Ethiopia Ministry of Health; 2012.

17. President's Malaria Initiative Ethiopia. Malaria Operational Plan FY. Addis Ababa: President's malaria initiative Ethiopia; 2020.

18. Ayalew MB. Therapeutic efficacy of artemether-lumefantrine in the treatment of uncomplicated Plasmodium falciparum malaria in Ethiopia: a systematic review and meta-analysis. Infect Dis Poverty. 2017;6:157.

19. Gebreyohannes EA, Bhagavathula AS, Seid MA, Tegegn HG. Anti-malarial treatment outcomes in Ethiopia: a systematic review and meta-analysis. Malar J. 2017;16:269.

20. Moher D, Liberati A, Tetzlaff J, Altman DG, PRISMA Group. Preferred reporting items for systematic reviews and meta-analyses: the PRISMA Statement. BMJ. 2009:339:b2535.

21. Abamecha A, Yilma A, Addisu W, Yewhalaw D, Abdissa A. Monitoring of efficacy and safety of artemether-lumefantrine for treatment of uncomplicated $P$. falciparum malaria in Ethiopia: a systematic review and meta-analysis of the evidence. PROSPERO 2020 CRD42020201859.https:// www.crd.york.ac.uk/prospero/display_record.php?ID=CRD42020201859. Accessed 3 Aug 2020

22. Higgins JPT, Thomas J, Chandler J, Cumpston M, Li T, Page MJ, Welch VA (editors). Cochrane handbook for systematic reviews of interventions version 6.0 (updated July 2019). Cochrane; 2019. www.training.cochrane. org/handbook. Accessed 3 Mar 2020

23. The Cochrane Collaboration. Cochrane handbook for systematic reviews of interventions version 5.1.0 (2011); 2011. http://handbook.cochrane. org/. Accessed 3 Mar 2020

24. Federal Ministry of Health of Ethiopia. Malaria diagnosis and treatment guidelines for health workers. Addis Ababa: Federal Ministry of Health of Ethiopia; 2004.

25. Lefebvre C, Manheimer E, Glanville J. Searching for studies. In: Higgins JPT, Greene S, Cochrane handbook for systematic reviews of interventions, Version 5.0. eds; 2008.

26. Wells GA, Shea B, O'Connell D, Peterson J, Welch V, Losos M, Tugwell P. The Newcastle-Ottawa Scale (NOS) for assessing the quality if nonrandomized studies in meta-analyses; 2012. http://www.ohrica/programs/clini cal_epidemiology/oxfordasp. Accessed 2 Dec 2020

27. Jadad AR, Moore RA, Carroll D, Jenkinson C, Reynolds DJ, Gavaghan DJ, et al. Assessing the quality of reports of randomized clinical trials: is blinding necessary? Control Clin Trials. 1996;17:1-12.

28. Sterne JA, Hernán MA, Reeves BC, Savović J, Berkman ND, Viswanathan M, et al. ROBINS-I: a tool for assessing risk of bias in non-randomised studies of interventions. BMJ. 2016;355:i4919.

29. Open-Meta-Analyst. http://www.cebm.brown.edu/openmeta/doc/ openMA_help.html\#self. Accessed 3 Mar 2020

30. Wallace BC, Schmid CH, Lau J, Trikalinos TA. Meta-Analyst: software for meta-analysis of binary, continuous and diagnostic data. BMC Med Res Methodol. 2009;9:80.

31. Ryan R. Cochrane Consumers and Communication Review Group. Heterogeneity and subgroup analyses in Cochrane Consumers and Communication Group reviews: planning the analysis at protocol stage; 2016. http://cccrg.cochrane.org. Accessed 12 Feb 2019

32. Kontopantelis E, Springate DA, Reeves D. A re-analysis of the Cochrane Library Data: the dangers of unobserved heterogeneity in meta-analyses. PLoS ONE. 2013;8:e69930.

33. Higgins JPT, Thompson SG. Quantifying heterogeneity in a meta-analysis. Stat Med. 2002;21:1539-58.

34. Jima D, Tesfaye G, Medhin A, Kebede A, Argaw D, Babaniyi O. Safety and efficacy of artemether-lumefantrine in the treatment of uncomplicated falciparum malaria in Ethiopia. East Afr Med J. 2005;82:387-90

35. Abamecha A, Yilma D, Addisu W, El-Abid H, Ibenthal A, Noedl H, et al. Therapeutic efficacy of artemether-lumefantrine in the treatment of uncomplicated Plasmodium falciparum malaria in Chewaka District, Ethiopia. Malar J. 2020;19:240.

36. Eshetu T, Abdo N, Bedru KH, Fekadu S, Wieser A, Pritsch M, et al. Openlabel trial with artemether-lumefantrine against uncomplicated Plasmodium falciparum malaria three years after its broad introduction in Jimma Zone, Ethiopia. Malar J. 2012;11:240.
37. Hwang J, Alemayehu BH, Hoos D, Melaku Z, Tekleyohannes SG, Teshi T, et al. In vivo efficacy of artemether-lumefantrine against uncomplicated Plasmodium falciparum malaria in Central Ethiopia. Malar J. 2011;10:209.

38. Mekonnen SK, Medhin G, Berhe N, Clouse RM, Aseffa A. Efficacy of artemether-lumefantrine therapy for the treatment of uncomplicated Plasmodium falciparum malaria in Southwestern Ethiopia. Malar J. 2015;14:317.

39. Nega D, Assefa A, Mohamed H, Solomon H, Woyessa A, Assefa Y, et al. Therapeutic efficacy of artemether-lumefantrine $\left(\mathrm{Coartem}^{\circledR}\right)$ in treating uncomplicated P falciparum malaria in Metehara, Eastern Ethiopia: regulatory clinical study. PLoS ONE. 2016;11:e0154618.

40. Getnet G, Fola AA, Alemu A, Getie S, Fuehrer HP, Noedl H. Therapeutic efficacy of artemether-lumefantrine for the treatment of uncomplicated Plasmodium falciparum malaria in Enfranze, north-west Ethiopia. Malar J. 2015;14:258.

41. Assefa A, Kassa M, Tadese G, Mohamed H, Animut A, Mengesha T. Therapeutic efficacy of artemether/lumefantrine $\left(\right.$ Coartem $\left.^{\circledR}\right)$ against Plasmodium falciparum in Kersa, South West Ethiopia. Parasit Vectors. 2010;3:1.

42. Deressa T, Seid ME, Birhan W, Aleka Y, Tebeje BM. In vivo efficacy of artemether-lumefantrine against uncomplicated Plasmodium falciparum malaria in Dembia District, northwest Ethiopia. Ther Clin Risk Manag. 2017;13:201-6.

43. Kinfu G, Gebre-selassie S, Fikrie N. Therapeutic efficacy of artemetherlumefantrine for the treatment of uncomplicated Plasmodium falciparum malaria in Northern Ethiopia. Malar Res Treat. 2012;2012:548710.

44. Teklemariam M, Assefa A, Kassa M, Mohammed H, Mamo H. Therapeutic efficacy of artemether-lumefantrine against uncomplicated Plasmodium falciparum malaria in a high-transmission area in northwest Ethiopia. PLOS ONE. 2017;12:e0176004.

45. Mulu A, Geresu B, Beyene Y, Ademe M. Efficacy of artemetherlumefantrine for the treatment of uncomplicated Plasmodium falciparum malaria in Northeast Ethiopia. Int J Basic Clin Pharmacol. 2015;4:492-6.

46. Kefyalew T, Animut A, Tamene T, Jima D, Hailemariam A, Legesse M. Efficacy of six-dose regimen of artemether-lumefantrine for the treatment of uncomplicated falciparum malaria, three years after its introduction into Ethiopia. Parasite. 2009;16:129-34.

47. Ebstie YA, Zeynudin A, Belachew T, Desalegn Z, Suleman S. Assessment of therapeutic efficacy and safety of artemether-lumefantrine $\left(\right.$ Coartem $\left.^{\circledR}\right)$ in the treatment of uncomplicated Plasmodium falciparum malaria patients in Bahir Dar district, Northwest Ethiopia: an observational cohort study. Malar J. 2015:14:236.

48. Kanche ZZ, Woticha EW, Gidebo KD. Therapeutic efficacy and safety of artemether-lumefantrine (Coartem ${ }^{\circledR}$ ) in uncomplicated Plasmodium falciparum malaria in Wolaita Zone, Southern Ethiopia. J Biol Agric Healthc. 2016:6:42-8.

49. Wudneh F, Assefa A, Nega D, Mohammed H, Solomon H, Kebede T, et al. Open-label trial on efficacy of artemether/lumefantrine against the uncomplicated Plasmodium falciparum malaria in Metema district, Northwestern Ethiopia. Ther Clin Risk Manag. 2016;12:1293-300.

50. Adam I, Ibrahim Y, Gasim Gl. Efficacy and safety of artemisinin-based combination therapy for uncomplicated Plasmodium falciparum malaria in Sudan: a systematic review and meta-analysis. Malar J. 2018;17:110.

51. Ngasala BE, Malmberg M, Carlsson AM, Ferreira PE, Petzold MG, Blessborn $D$, et al. Efficacy and effectiveness of artemether-lumefantrine after initial and repeated treatment in children $<5$ years of age with acute uncomplicated Plasmodium falciparummalaria in rural Tanzania: a randomized trial. Clin Infect Dis. 2011;52:873-82.

52. Plucinski MM, Talundzic E, Morton L, Dimbu PR, Macaia AP, Fortes F, et al. Efficacy of artemether-lumefantrine and dihydroartemisinin-piperaquine for the treatment of uncomplicated malaria in children in Zaire and Uíge Provinces, Angola. Antimicrob Agents Chemother. 2015;59:437-43.

53. Okell LC, Cairns M, Griffin JT, Ferguson NM, Tarning J, Jagoe G, et al. Contrasting benefits of different artemisinin combination therapies as firstline malaria treatments using model-based cost-effectiveness analysis. Nat Commun. 2014;5:5606. 
54. WHO. World malaria report. Geneva: World Health Organization; 2018.

55. WHO. Policy Brief on single-dose primaquine as a gametocytocide in Plasmodium falciparum malaria. Geneva: World Health Organization; 2015.

56. WWARN Artemisinin based Combination Therapy (ACT) Africa Baseline Study Group, Dahal P, Dalessandro U, Dorsey G, Guerin PJ, Nsanzabana C, et al. Clinical determinants of early parasitological response to ACTs in African patients with uncomplicated falciparum malaria: a literature review and meta-analysis of individual patient data. BMC Med. 2015;13:212.

57. WHO. Global plan for artemisinin resistance containment (GPARC). Geneva: World Health Organization; 2011.
58. Shayo A, Buza J, Ishengoma DS. Monitoring of efficacy and safety of artemisinin-based anti-malarials for treatment of uncomplicated malaria: a review of evidence of implementation of anti-malarial therapeutic efficacy trials in Tanzania. Malar J. 2015;14:135.

\section{Publisher's Note}

Springer Nature remains neutral with regard to jurisdictional claims in published maps and institutional affiliations.
Ready to submit your research? Choose BMC and benefit from:

- fast, convenient online submission

- thorough peer review by experienced researchers in your field

- rapid publication on acceptance

- support for research data, including large and complex data types

- gold Open Access which fosters wider collaboration and increased citations

- maximum visibility for your research: over $100 \mathrm{M}$ website views per year

At BMC, research is always in progress.

Learn more biomedcentral.com/submissions 